\title{
Limitation of the use of inert gases in the measurement of small gut mucosal blood flow
}

\author{
J. D. HAMILTON, A. M. DAWSON, AND JOAN WEBB \\ From St. Bartholomew's Hospital, London, E.C.1
}

EDITORIAL COMMENT The measurement of blood flow in the small intestine, calculated from ${ }^{133}$ Xenon disappearance rates, has shown values to be much lower than those obtained by other methods. The reasons for this disappointing finding are discussed.

The role of blood flow in absorption from the small gut would be best studied by a method able to measure exclusively blood flow in the small gut mucosa because this might vary independently of total small gut blood flow. Such a method should be repeatable to give values in control and experimental periods, and one would hope that it would be adaptable for use in man.

We had hoped to meet these criteria by measuring the rate of removal of ${ }^{133}$ Xenon from fluid in the lumen of the small gut. Kety (1951) has described the factors involved in the use of inert gases to measure tissue blood flow. In muscle (e.g., Lassen, Høedt-Rasmussen, Lindjberg, Pedersen, and Munck, 1963), myocardium (e.g., Ross, Ueda, Lichtlen, and Rees, 1964), and brain (e.g., Lassen and Klee, 1956) blood flow has been measured from the rate of disappearance of radioactive inert gases out of the tissue. The validity of these methods depends upon the assumption that diffusion of gas through the tissue is so fast that it does not delay its removal, which is therefore dependent only upon blood flow. In the gut, if the same assumption holds true, then when the gas is dissolved in fluid placed in the gut lumen, the rate of its removal will be proportional to blood flow in the mucosa, and will be unaffected by blood flow in any other part of the gut wall.

METHODS

The rate of removal of ${ }^{133}$ Xenon from loops of small gut was measured in 19 dogs (13 mongrel, 8 to $28 \mathrm{~kg}$.; six greyhound, 20 to $30 \mathrm{~kg}$.). They were starved overnight, anaesthetized with intravenous pentobarbitone $(60 \mathrm{mg}$. per kg.), intubated and ventilated with nitrous oxide and oxygen by a mechanical pump (C. F. Palmer (London) Limited). Arterial blood $\mathrm{PCO}_{2}$ and $\mathrm{PO}_{2}$ were measured at intervals, and inspired oxygen concentration and ventilation were adjusted to maintain a $\mathrm{PaCO}_{2}$ of 35 to $40 \mathrm{~mm}$. $\mathrm{Hg}$ and a $\mathrm{PaO}_{2}$ of 100 to $140 \mathrm{~mm}$. Hg. Mean arterial blood pressure was measured from an arterial cannula by a mercury manometer. Rectal temperature was controlled to 38 to $39^{\circ} \mathrm{C}$.

Closed loops of small gut were constructed at laparotomy by a method adapted from that of Code, Bass, McClary, Newnum, and Orvis (1960). Lengths of intestine were selected so that they were supplied by a main mesenteric artery branch. Through incisions in the wall of the bowel two Perspex bobbins were placed either 10 or $20 \mathrm{~cm}$. apart in the lumen, and the small gut wall was tied over these with tape. These tapes also occluded any marginal anastomotic vessels. A polyvinyl tube cemented through one bobbin drained the inside of the loop bounded by the bobbins, and was brought out through the incisions and onto the surface of the abdomen so that the loop could be filled and emptied. Gut incisions were closed and the loops were replaced in the abdomen and finally the abdomen was closed. All fluids to be placed in the loop were warmed to $38^{\circ} \mathrm{C}$. in a waterbath and were isotonic. The loops were washed clear of debris and air bubbles with isotonic saline. A Panax type 5054 Geiger-Muller detector connected to a plain recorder was fixed outside the abdomen and over the loop. A long time constant of 25 seconds was used to smooth out the minor effects of respiratory movement upon the position of the loop beneath the counter. After a recovery period of 30 minutes, the loop was filled with 10 or $20 \mathrm{ml}$. of isotonic saline or isotonic mannitol (hereafter, for convenience, referred to as 'luminal fluid') in which had been dissolved ${ }^{133}$ Xenon (Radiochemical Centre, Amersham). The disappearance of the total radioactivity from the loop was then recorded. Finally the loop was washed clear of Xenon and a background activity recorded. It was confirmed that only a negligible amount of Xenon dissolved in the bobbin and tubing. Measurements were not used if there had been a major absorption of fluid. To prevent accumulation of Xenon in the body, an open anaesthetic circuit was used, and to prevent contamination of room air, expired air was led out of a window by a tube. 
Pittinger, Conn, Featherstone, Stickley, Levy, and Cullen (1956) have shown that Xenon is almost totally removed from the blood during its passage through the lungs. Moreover, since the blood flow to experimental loops of gut was only a very small proportion of the total cardiac output, errors due to incomplete removal of Xenon in the lungs and consequent arterial accumulation would be negligible. The disappearance curves obtained were mono-exponential, as shown in Figure 1. From the slope of the log plot was measured rate of removal of Xenon, expressed as percentage removal per minute.

CALCULATION OF MUCOSAL BLOOD FLOW If we assume that the removal of Xenon is dependent only upon mucosal blood flow, then:

Mucosal blood flow (ml./min.) =

$$
\frac{\% \text { removal } / \mathrm{min} .}{100} \times \frac{\text { vol. saline }(\mathrm{ml} .)}{\mathrm{P}}
$$

where $\mathbf{P}=$ partition coefficient for Xenon between saline and blood. This depends mainly upon the haemoglobin concentration, because of the high solubility of Xenon in red cells.

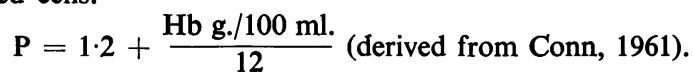

Haemoglobin concentrations were 13 to 15 g. per $100 \mathrm{ml}$. in mongrels and 15 to $18 \mathrm{~g}$. per $100 \mathrm{ml}$. in greyhounds.

Total blood flow through the loop was measured by collecting the venous effluent into a graduated cylinder. For these experiments, the loop was sited so that all the venous blood drained into a single vein. A wide Teflon cannula was inserted into the next proximal tributary of

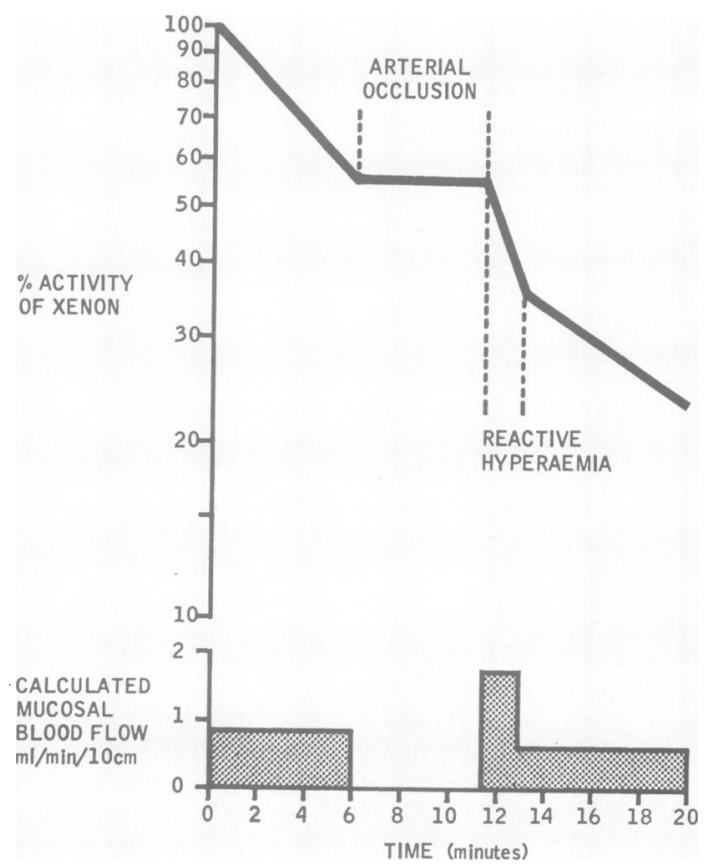

FIG. 1. Effect of arterial occlusion on Xenon disappearance from small gut loop and its calculated mucosal blood flow.

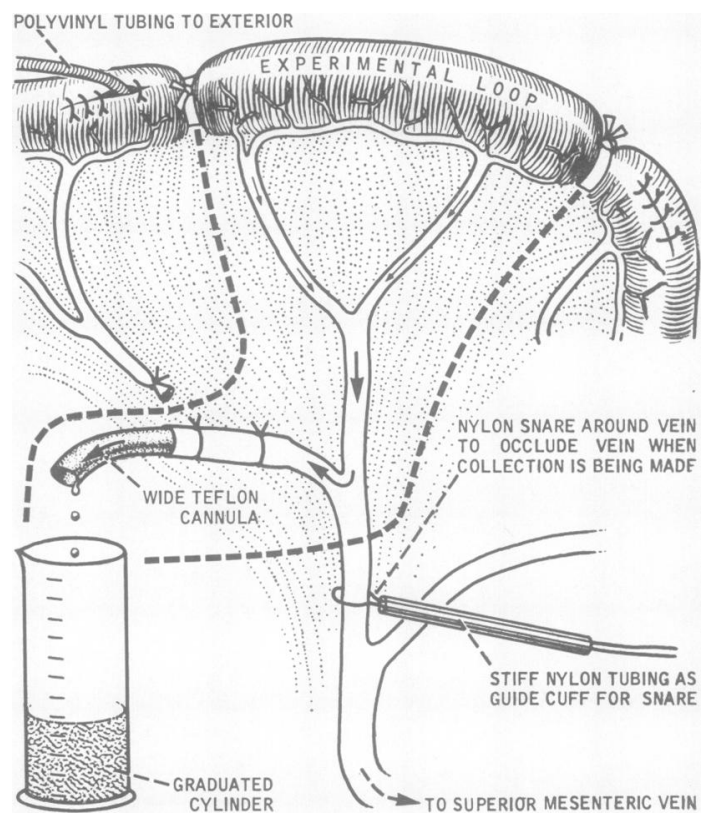

FIG. 2. Method for collecting venous effluent from an experimental loop of small gut. During collection the nylon snare is tightened to divert blood through the cannula.

this vein and a snare was placed proximal to the junction of this tributary with the main vein, so that when the snare was tightened the total venous outflow from the loop was diverted through the cannula for measurement of flow rate and of $\mathrm{PO}_{2}$. This technique is illustrated in Figure 2. Vasopressin, $\mathbf{0 . 2} \mathrm{u}$./minute, or bradykinin, $0.6 \mu \mathrm{g}$./minute, was infused into the artery supplying the loop. To avoid damage to the main vessel this was cannulated retrogradely through a small nearby branch which did not supply the loop.

Lumen oxygen pressure was measured in the loops by the method of Dawson, Trenchard, and Guz (1965). Twenty ml. of deoxygenated lumen fluid was placed in the loop and then every 10 minutes, after discarding the fluid occupying the dead space, $2 \mathrm{ml}$. samples were withdrawn, and their $\mathrm{PO}_{2}$ was measured. After 30 minutes a plateau was usually reached, and this was taken as the integrated 'mucosal $\mathrm{PO}_{2}$ '. A fuller analysis of findings relating to $\mathrm{PO}_{2}$ and $\mathrm{PCO}_{2}$ will be presented elsewhere.

All gas pressure measurements were made on a ClarkSeveringhaus electrode assembly. At the end of experiments loops were opened, laid out flat and their surface area was measured.

The anatomy of the circulation of the dog small gut was studied in two ways, both similar to the techniques of Jacobson and Noer (1952).

1 Casts of the vascular bed were made with 1562 Latex (Breon Nitriles) coloured with Irgalate paste (Geigy U.K. Limited). A length of intestine was excised, its vein and artery cannulated, and after an initial perfusion with $0.01 \%$ potassium nitrate in saline as a vasodilator, red and blue latex was injected simultaneously into artery and 
vein respectively at a pressure of $140 \mathrm{~mm}$. $\mathrm{Hg}$. This pressure was maintained for 10 minutes and the vessels were then tied off and the loop immersed in $\mathrm{N} / 10$ hydrochloric acid, to solidify the latex. Subsequently the cast was examined under a dissecting microscope, both before and after digestion of tissue with hot concentrated $\mathbf{H C l}$. Usually a cast of the total capillary bed was obtained. 2 Coomasie blue dye was injected as a bolus into the mesenteric artery and its passage through the villi of an opened loop watched through a dissecting microscope.

The rate of diffusion of ${ }^{133}$ Xenon relative to that of $\mathrm{CO}_{2}$ and $\mathrm{O}_{2}$ was measured at room temperature through the membraneous part of rabbit mesentery. Ten $\mathrm{ml}$. of isotonic saline, previously equilibrated with $25 \% \mathrm{CO}_{2}$ in $\mathrm{O}_{2}$, was mixed with $2 \mathrm{ml}$. of saline containing Xenon, and the $\mathrm{PO}_{2}$ and $\mathrm{PCO}_{2}$ of the mixture were measured. A screw cap top from a specimen bottle was filled with the saline mixture and a magnetic 'flea' added. The membrane was lowered onto the cap and fixed by an elastic band, so that air bubbles were excluded. This assembly was rinsed briefly in saline and its rate of $\gamma$ emission counted for one minute. It was then placed over a magnetic stirrer (1,000 rev./min.) in a bath containing 6 litres of isotonic saline, constantly mixed by a pump. The membrane was thus separating two rapidly mixed saline compartments. After 10 minutes the assembly was removed again, and the radioactivity (Xenon), $\mathrm{PCO}_{2}$, and $\mathrm{PO}_{2}$ were again measured. In separate experiments it was found that the delay during construction of the assembly and radioactivity counting allowed only minor changes of $\mathrm{PCO}_{2}$ and $\mathrm{PO}_{2}$. The accumulation of gas in the 6 litre bath would be negligible and only $\mathrm{PO}_{2}$ values need correction, by subtracting atmospheric $\mathrm{PO}_{2}$. Then, when the initial and final readings of pressure or activity are plotted on a log scale against time on a plain scale, their exponential rates of disappearance are reconstructed. The relative slopes of these lines are the relative rates of diffusion of the three gases since they are all measured under the same conditions and through the same membrane.

\section{TABLE I}

THE RELATIVE RATES OF DIFFUSION OF XENON, $\mathrm{CO}_{2}, \mathrm{O}_{2}$ THROUGH RABBIT MESENTERY MEASURED BY THE METHOD DESCRIBED IN THE TEXT

\begin{tabular}{llll} 
Experiment Number & \multicolumn{3}{l}{ Relative Rates of Diffusion } \\
\cline { 2 - 4 } & Xenon & $\mathrm{CO}_{2}$ & $\mathrm{O}_{2}$ \\
\hline I & 1 & 1.43 & 1.14 \\
II & 1 & 1.6 & 1.35 \\
III & 1 & 2.3 & 2.16 \\
Average & 1 & 1.4 & 1.45 \\
$\begin{array}{l}\text { Expected rates from atomic } \\
\quad \text { weights }\end{array}$ & 1 & 1.68 & 1.53 \\
$\begin{array}{l}\text { Rates of diffusion through } \\
\text { hydrated gelatin measured by } \\
\text { Jones (1950) }\end{array}$ & 1 & 1.7 & 2 \\
& 1 & 2.08 &
\end{tabular}

\section{RESULTS AND COMMENTS}

In 30 experiments in 14 dogs with normal mean blood pressure (about $135 \mathrm{~mm}$. $\mathrm{Hg}$ ), values for apparent mucosal blood flow were within the range
0.1 to $0.7 \mathrm{ml} . / \mathrm{min} . / 10 \mathrm{~cm}$. of gut or 0.005 to $0.03 \mathrm{ml} . / \mathrm{min}$. sq. $\mathrm{cm}$. of mucosa. As these values were much lower than those obtained by workers using other methods (Grim, 1964), the validity of this method was tested in three groups of experiments.

REACTIVE HYPERAEMIA This was induced in four experiments by temporary occlusion of the arterial supply to the loop for five to 10 minutes. This is a standard test of Xenon removal as a measure of blood flow and has been used in muscle (e.g., Lassen et al., 1963).

Figure 1 shows the result of a representative experiment. During arterial occlusion Xenon was not removed; on releasing the artery removal was very rapid, lasting two to three minutes. Results of all four experiments are shown in Table II. At

\section{TABLE II}

RATES OF REMOVAL OF XENON ( $\%$ /MINUTE) FROM LOOPS OF SMALL GUT DURING EXPERIMENTS ON REACTIVE HYPERAEMIA $^{1}$

\begin{tabular}{|c|c|c|c|c|c|}
\hline \multirow{2}{*}{$\begin{array}{l}\text { Dog } \\
\text { No. }\end{array}$} & \multicolumn{2}{|c|}{ Occlusion } & \multirow{2}{*}{$\begin{array}{l}\text { Immediately } \\
\text { after Release } \\
\text { of Clamp }\end{array}$} & \multirow{2}{*}{$\begin{array}{l}\text { Recovery } \\
\text { Period }\end{array}$} & \multirow{2}{*}{$\begin{array}{l}\text { Length of } \\
\text { Period of } \\
\text { Rapid Re- } \\
\text { moval (min.) }\end{array}$} \\
\hline & Before & During & & & \\
\hline 1 & 7 & 0 & 14 & 0 & 3 \\
\hline 2 & 11 & 0 & $17 \cdot 5$ & 7 & $2 \cdot 5$ \\
\hline 3 & 6.5 & 1 & 13 & 2 & 3 \\
\hline 4 & $9 \cdot 5$ & 0 & 13 & 3.5 & 2 \\
\hline
\end{tabular}

${ }^{1}$ The artery supplying the loop was occluded by a nylon snare for five minutes as described in the text.

separate experiments with an opened loop, the arterial occlusion caused intense mucosal pallor and cessation of venous outflow. Release of the occlusion caused for three minutes intense mucosal hyperaemia and a rise of venous outflow to twice the control value. It thus seemed that in these experiments, removal of Xenon behaved qualitatively as if it were dependent on blood flow.

VASOCONSTRICTION AND VASODILATATION These were induced by intraarterial infusion of vasopressin and bradykinin respectively for 10 minutes. With bradykinin, there was an increase in total blood flow and hyperaemia of the mucosa, but no consistent rise in the rate of removal of Xenon. With vasopressin there was a decrease in total blood flow and blanching of the mucosa but no consistent fall in the rate of removal of Xenon. Figure 3 demonstrates this lack of correlation when Xenon removal and total blood flow were measured simultaneously.

The data of Fig. 3 imply that the mucosa receives only 2 to $5 \%$ of the total blood flow. This is a much 


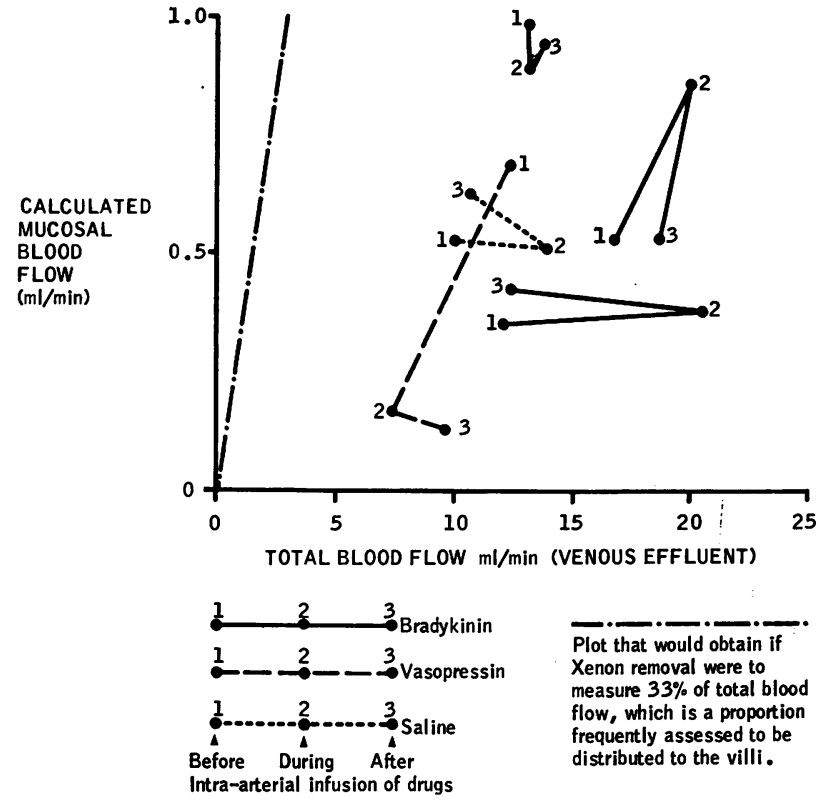

FIG. 3. Effect of intra-arterial vasoactive drugs on calculated mucosal blood flow and total blood flow of $12 \mathrm{~cm}$. small gut loop.

smaller proportion than the 30 to $40 \%$ that has been found by other workers using a variety of methods, e.g., injection of glass microspheres (Lindseth, 1960) and deuterium oxide distribution (Rayner, MacLean, and Grim, 1960; Weiner, 1961).

The conclusions drawn from these two groups of experiments conflict. Xenon removal behaved qualitatively as if it were blood flow dependent when blood flow was altered by inducing reactive hyperaemia, but not when it was altered by vasoactive drugs. Quantitatively, the values obtained were much smaller than expected. The reasons for these conflicting conclusions will be discussed later. To test further the validity of the method, we carried out experiments using lumen $\mathrm{PO}_{2}$ as an alternative indicator of villous blood flow.

LUMEN $\mathrm{PO}_{2}$ AS AN ALTERNATIVE INDICATOR OF MUCOSAL BLOOD FLOW The $\mathrm{O}_{2}$ consumption of loops of gut was measured by the Fick principle, using arteriovenous oxygen content difference and flow rate. It remained very constant under a wide range of blood flows (Fig. 4). It is likely that the same is true of the mucosa, in which case changes in mucosal blood flow would be reflected by changes in lumen (i.e., mucosal) $\mathrm{PO}_{2}$, which is the result of the balance between oxygen supply and oxygen utilization. Lumen $\mathrm{PO}_{2}$ and ${ }^{133}$ Xenon removal were measured in the same loop alternately. Figure 5 shows that there was no correlation between them. The $\mathrm{PO}_{2}$ changes were spontaneous and will be reported elsewhere.

These investigations show that although the exponential disappearance of Xenon, and the experiments with reactive hyperaemia were suggestive that removal of Xenon was dependent on blood flow, all the other experiments contradicted this assumption, and one must conclude that factors quantitatively more important than blood flow must influence the removal of Xenon. These factors will now be discussed.

\section{CONSIDERATION OF FACTORS AFFECTING THE REMOVAL} OF ${ }^{133}$ XENON FROM THE GUT LUMEN

THE RATE OF DIFFUSION OF XENON When Xenon is removed from the lumen fluid by the blood, it must first diffuse across the epithelial cell, which is $25 \mu$
FIG. 4. The relation between oxygen utilization and blood flow in a loop of small gut.

spontaneous changes of blood flow. $\bigcirc$ blood flow changes induced by vasoactive drugs.

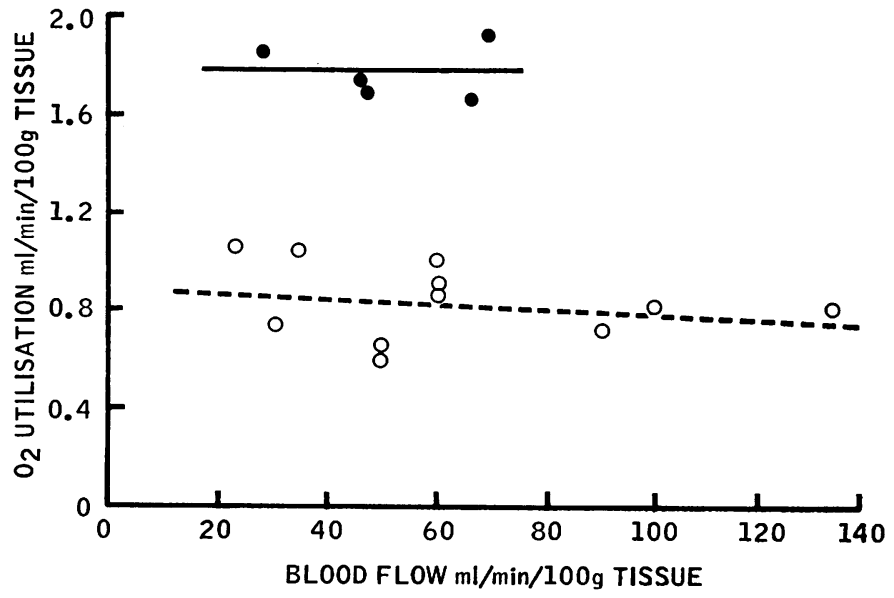




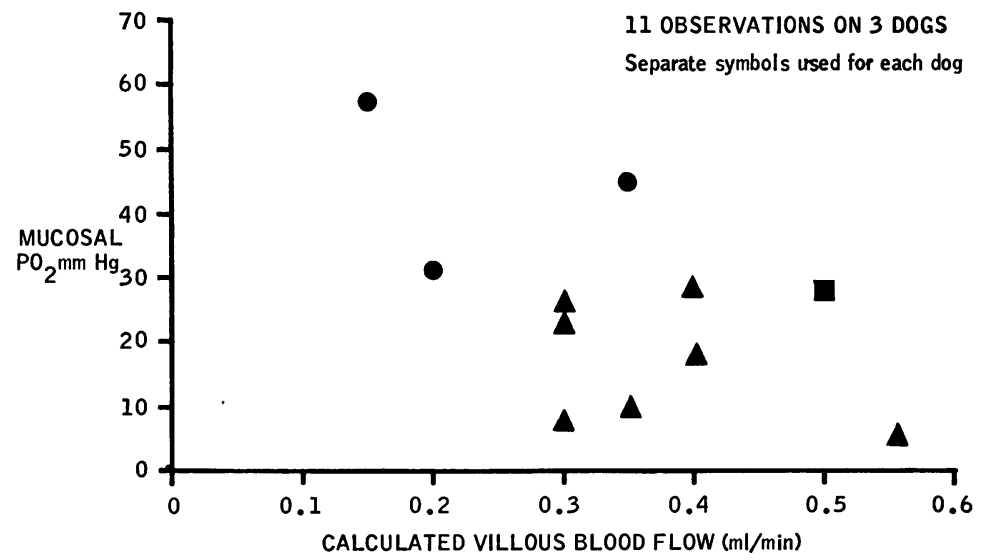

FIG. 5. The relation between apparent villous blood flow and lumen oxygen tension in small gut loops. Blood flow is related to 10 cm. length of gut.

thick. In the lung, diffusion across the alveolar membrane $(1 \mu$ thick $)$ is so fast that it does not interfere with gas uptake by the blood. But the same cannot necessarily be assumed for diffusion across the thicker epithelial cell in the gut.

The surface area available for diffusion into the epithelial cell layer is, for the total villous surface of a $10 \mathrm{~cm}$. loop, about $460 \mathrm{sq}$. cm. (see appendix). The area for diffusion into the capillaries, however, is less than this: they are spread like a net over the relatively narrow villous core, and have on our observations on latex casts a surface area probably no more than one quarter that of the external epithelial cell, i.e., about 110 sq. cm. Gas, therefore, diffuses from an outer cell surface area of $460 \mathrm{sq} . \mathrm{cm}$. to the smaller capillary surface area of $110 \mathrm{sq}$. $\mathrm{cm}$.
In calculations on the rate of diffusion, therefore, approximately the mean of these values must be used as an 'effective' surface area, i.e., about 280 sq. $\mathrm{cm}$.

Figure 6 shows the way in which a diffusion barrier affects the relationship between blood flow and the rate of removal of Xenon. Values are given for a lumen concentration of $1 \mathrm{unit} / \mathrm{ml}$. and a saline:blood partition coefficient of $2 \cdot 5$. This graph assumes that the saline phase and blood phase are both continuously mixed. AB represents the plot as if for a theoretical system with no epithelial cell layer (the removal of Xenon is entirely blood flow dependent). $\mathrm{AC}$ represents the system as it is; $\mathrm{AC}$ diverges from $A B$ towards $X Y$, which represents the maximum rate of removal that could be achieved through this

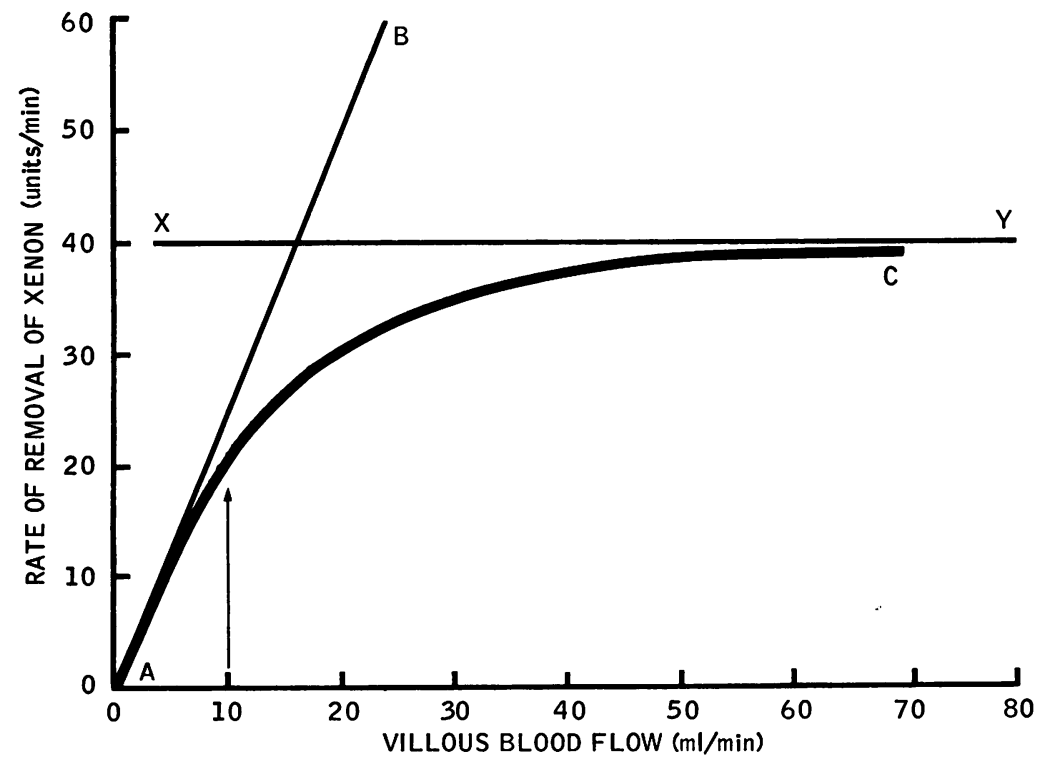

FIG. 6. The calculated relation between villous blood flow and rate of removal of Xenon in a 10 $\mathrm{cm}$. loop of small gut containing $10 \mathrm{ml}$. of fluid (for explanation see text). 
diffusion barrier even at infinite blood flow, when the effective capillary Xenon concentration would be zero. This maximum rate is determined by the dimensions of the epithelial cell layer and the coefficient of diffusion of Xenon through it. At low blood flows this clearance of Xenon is a fairly accurate and sensitive measure of blood flow. At higher flows it becomes less accurate and less sensitive as the plot diverges from $\mathrm{AB}$. If $\mathrm{XY}$ is low, i.e., the epithelial cells form a large diffusion barrier, then Xenon clearance is a measure of blood flow only at low flows. If, however, $\mathrm{XY}$ is high, i.e., a small diffusion barrier, then Xenon clearance remains a measure of blood flow up to high flows. In a $10 \mathrm{~cm}$. loop the maximum likely mucosal blood flow is $10 \mathrm{ml} . /$ minute and for $\mathrm{AC}$ to remain close to $\mathrm{AB}$ for blood flows up to this value, $\mathrm{XY}$ will have to be, as shown in Fig. 6, at least $40 \mathrm{u} . / \mathrm{min}$. The units used in these calculations are arbitrary units of quantity of Xenon. The thickness and effective surface area of the epithelial cell layer have been assessed, and the only unknown component affecting Xenon removal is the coefficient of diffusion of Xenon through the epithelial cell. As there appear to be no direct data on this we calculated what minimum value would have to be exceeded to allow $X Y$ to be $40 \mathrm{u} . / \mathrm{min}$.

Minimum coefficient of diffusion $=$

Maximum rate of diffusion (XY) (u./min.)

Concentration difference across cell (u./ml) $\times$

$$
\frac{\text { Cell thickness }(\mathrm{cm} .)}{\text { Effective surface area (sq. cm.) }} \times \frac{1}{60}
$$

and substituting values derived above:

$$
\begin{aligned}
& =\frac{40}{1} \times \frac{25 \times 10^{-4}}{280} \times \frac{1}{60} \\
& =0.6 \times 10^{-5} / \mathrm{cm} . / \mathrm{cm} .{ }^{2} / \mathrm{sec} . / \text { unit gradient. }
\end{aligned}
$$

Values for other gases in saline are, e.g.: $\mathrm{CO}_{2}: 1 \cdot 77$ $\times 10^{-5}$ and $\mathrm{O}_{2}=1.98 \times 10^{-5}$ (Geigy), and, by correcting for its higher molecular weight by Graham's law, an expected value for Xenon would be $1.0 \times$ $10^{-5}$ which is fast enough for the requirements of the calculations made above. Jones (1950) reports relative rates of diffusion for Xenon and other gases through water that are in agreement. We have obtained (Table I) values for relative diffusion coefficients through mesentery of the same order as those derived by calculation, although the relative rates for $\mathrm{CO}_{2}$ and $\mathrm{O}_{2}$ are reversed, as found in similar experiments by Krogh (1919).

We cannot, of course, necessarily assume that the diffusion through epithelial cells in the gut is at the same speed as through water or mesentery. But identical total body washout curves for inert gases with a wide range of diffusion coefficient have been found (Jones, 1950) and this suggests that as a general rule gas exchange is not diffusion limited in tissue. Longmuir and Bourke (1960) obtained a value for the coefficient of diffusion for oxygen in living cells that was faster than that through saline. They suggest that this is due to cytoplasmic streaming. The high solubility of Xenon in cell lipid would speed its diffusion through cell membranes. We can conclude that Xenon diffusion, whilst not instantaneous, is sufficiently fast for it not to interfere with its removal from the gut lumen by the blood.

Of the factors we assessed, one, the capillary surface area, might vary under different circumstances. With a low blood flow rate the capillaries would be narrow, as is seen on direct observation. The diffusion barrier for Xenon would then be bigger, but as the blood flow would also be small, it would be unlikely to make the removal of Xenon diffusion limited.

THE ACCESS OF XENON TO THE VILLOUS SURFACE Access of Xenon to the villous surface could be limited in two ways: (1) mixing might be slow within the lumen; this probably is not so because, as shown in Fig. 7, a gentle increase of mixing of lumen fluid caused no repeatable increase in rate of removal of

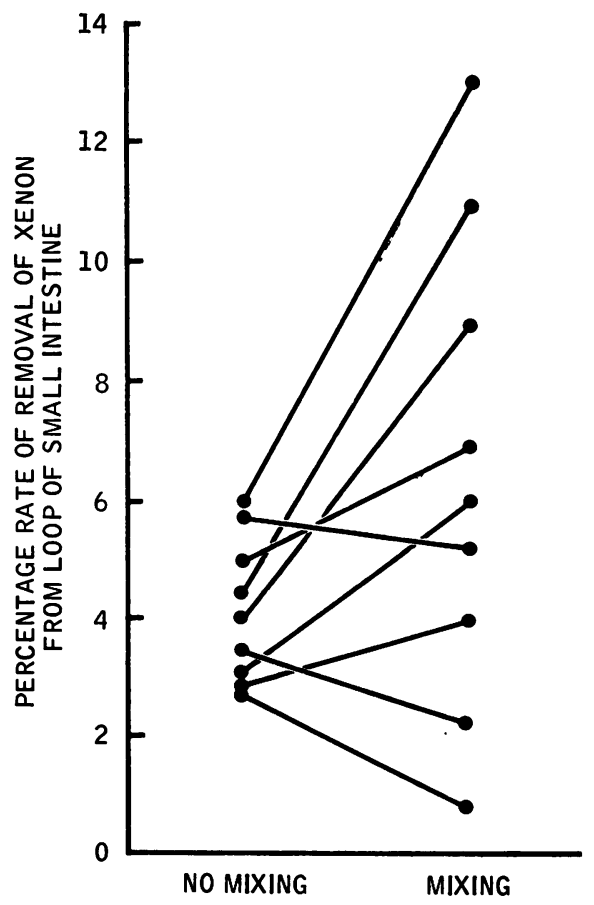

FIG. 7. The effect of mixing lumen fluid on rate of removal of lumen Xenon. 
Xenon. (2) Access of this mixed fluid to the total villous surface might be limited. This depends on anatomical factors:

Anatomy of the surface of the villi We observed the villi of an anaesthetized dog through a dissecting microscope and confirmed that they are long and tightly packed and that only the terminal quarter of their length is freely and continuously irrigated by lumen fluid. The adjacent quarter or third is partially or intermittently irrigated by bulk flows of fluid and by the active movements of peristalsis and the elongations and retractions of individual villi originally described by Hambleton (1914). The basal halves of the villi are almost entirely inaccessible to fluid in the lumen. Forcible separation of the villi by either a jet of fluid or an instrument causes an immediate reflex vasoconstriction and retraction of surrounding villi.

These studies also stress that lumen fluid has no access at all into the crypt area, and that blood perfusing it will remove no Xenon from the lumen. So it is only villous blood flow that is available for measurement, and the remaining discussion will be confined to this.

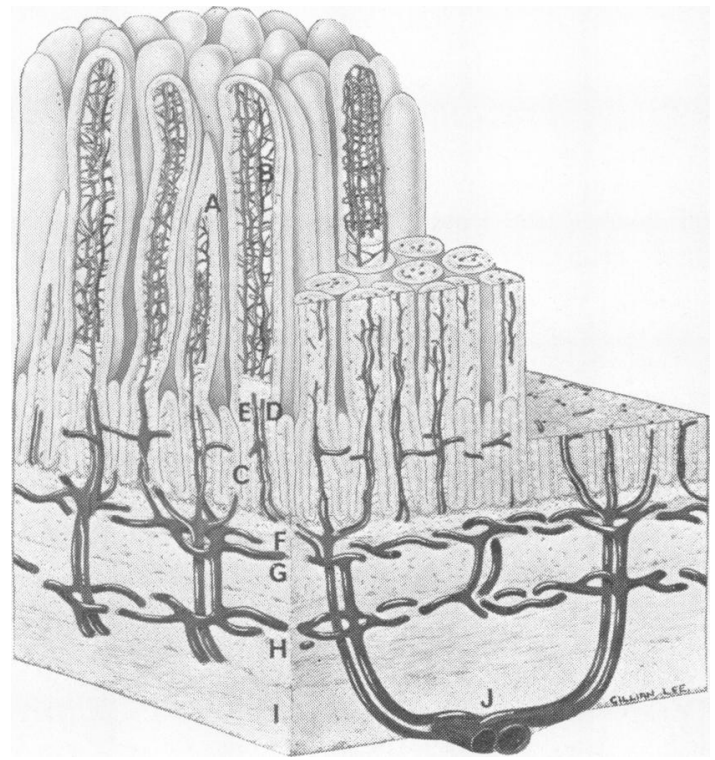

FIG. 8a. A stylized drawing of the vascular anatomy of the small gut of a dog. Arteries and veins run close to each other, from the subserosal circular vessels $(J)$ through longitudinal muscle $(I)$ and circular muscle $(H)$, and submucosa $(G)$ and muscularis mucosa $(F)$, at which level the villous arterioles $(D)$ arise and the villous venules $(E)$ join the inner venous plexus. Some villi $(A, B)$ are shown as if their central stroma had been removed. Other villi are shown cut transversely. Fine vessels supply the crypt area $(C)$. Each villus is in life about $1.5 \mathrm{~mm}$. long.
Anatomy of the circulation of the villi Figure 8 is a drawing of a typical cast of the blood vessels in a villus. Each villus is supplied by a single arteriole which is partially coiled, and runs from the submucosa straight to the tip of the villus. Throughout its course it gives off fine branches at right angles to itself. In the crypt area, these form a capillary mesh

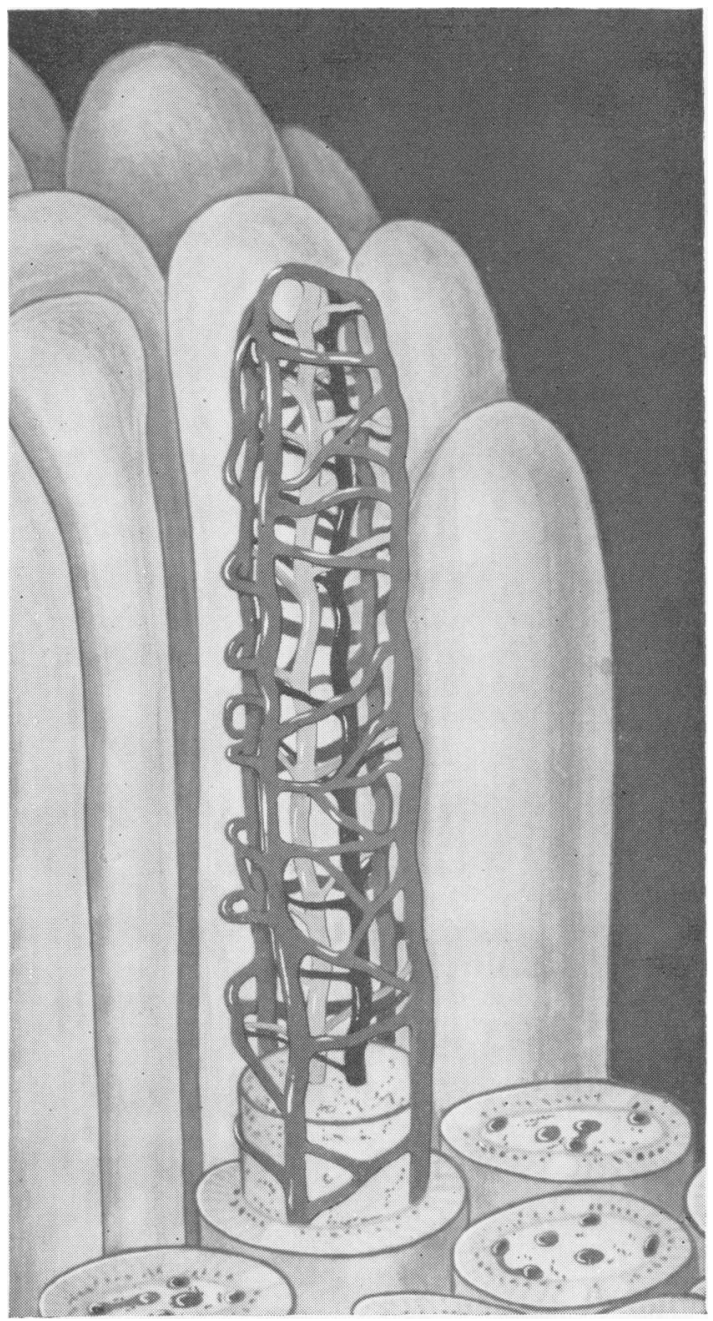

FIG. 8b. An enlarged view of the vasculature of the terminal millimetre of one villus of Figure 8a. Epithelial cells and stroma are shown as if dissected away from the vessels. For the sake of clarity, capillaries are shown as more sparse (about 50\%) than seen in actual specimens prepared by latex injection. The central arteriole (black) and venule (light grey) supply, by branches throughout their length, a capillary network (dark grey) that lies beneath the basement membrane of the epithelial cells. This capillary network has about four wide channels running longitudinally. 


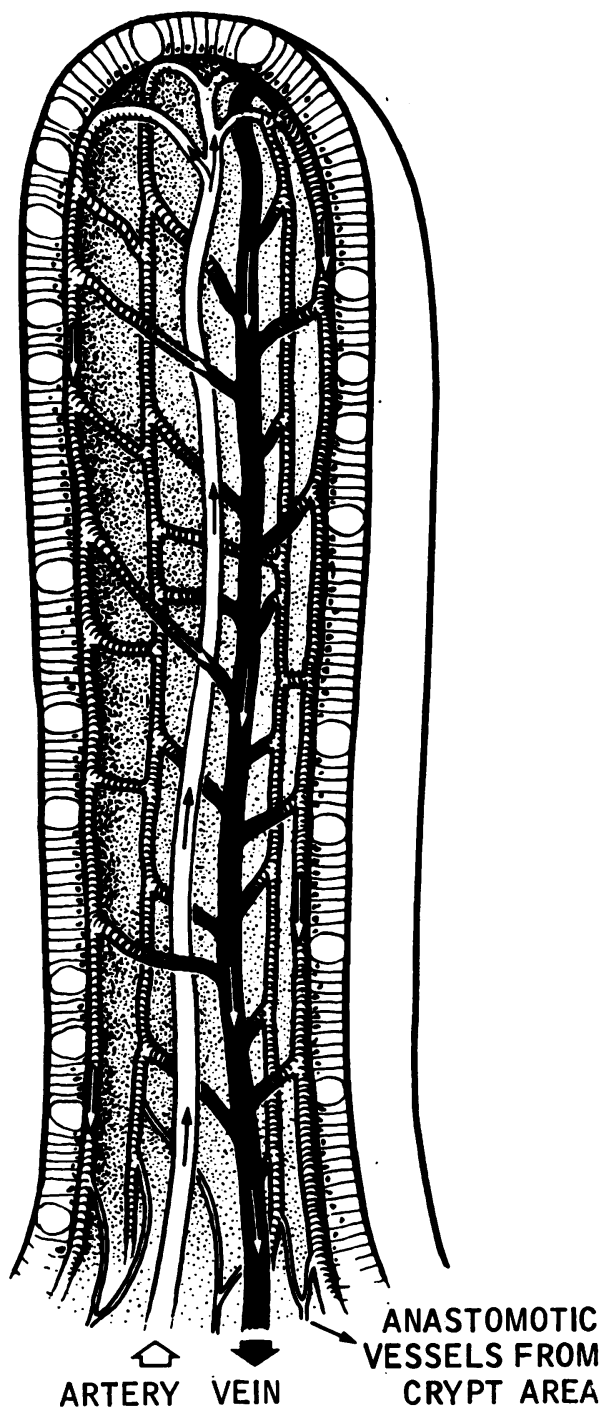

FIG. 9. The vascular anatomy of the villus of dog small gut as described by Jacobson and Noer (1952). They described no branches arising from the central arteriole during its course through the villus.

between the crypts. In the villus the branches feed a lacelike capillary network beneath the basement membrane of the epithelial layer. The villous venule arises at the tip of the villus, and runs down its core, receiving tributaries from the villous capillary net throughout its course. It runs on through the crypts and drains the capillary network there, and finally empties into submucosal veins which interconnect by wide anastomoses, forming a venous lake of large volume. This in turn drains into veins that, together with the villous arterioles, run through the smooth muscle of the wall towards the mesenteric border.

Our findings are not quite the same as those of other workers (e.g., Jacobson and Noer, 1952) who found no branches along most of the length of the villous arteriole. They suggested that the base of the villus was supplied by branches from the crypt area and the rest from the arteriolar branches arising at the tip of the villus, as illustrated in Figure 9. We found fine anastomoses between the capillaries of the crypts and villi, but no major branches, and it is likely that we were able to demonstrate the branches along the length of the villus because we dissected the casts under a microscope after digesting away all tissue - this latter was the most revealing of all the ways of examining the casts. Like Jacobson and Noer, we have been unable to demonstrate any arteriovenous anastomoses in any part of the small gut. Such anastomoses have been found in the stomach and it has been proposed that if they exist in the small gut they would allow shunting of blood away from the mucosa. The only suggestion of a low resistance pathway that we could find was in the villous tip, where one or two capillaries have a very short course between arteriole and venule, although they are not wider than other capillaries. From this type of preparation one cannot hazard an assessment of the functional significance of these capillaries, but they might provide a preferential pathway for blood perfusing the villous tip. The passage of Coomasie blue through the circulation of the villi confirms that each level of the villus is perfused by branches of the central arteriole arising at its own level and not simply from the base or the tip of the villus.

These are important observations for the analysis of the factors affecting the removal of Xenon, because it means that the blood perfusing each level of the villus can remove Xenon no faster than that at which it is presented to the overlying epithelium. As this is slow to the deeper levels of the villi, the rate of removal will give a corresponding underestimate of total blood flow in the villus.

Figure 6 (above) can be modified (Fig. 10) to show that limited access of lumen fluid to any level of the villus lowers the maximum possible rate of removal (XY) that can be achieved by blood perfusing that level, and so increases the divergence of $\mathrm{AC}$ from AB.

The difference between $X Y$ and $X^{\prime} Y^{\prime}$ represents for each level of the villus the degree of limitation of access. At the bases of the villi $X^{\prime} Y^{\prime}$ will approach zero, and at the tips it will be coincident with $X Y$. This effect is comparable to the effect in the lungs of underventilation upon the rate of gas transfer from ambient air to capillary blood.

The effect that the gradation of access will have 


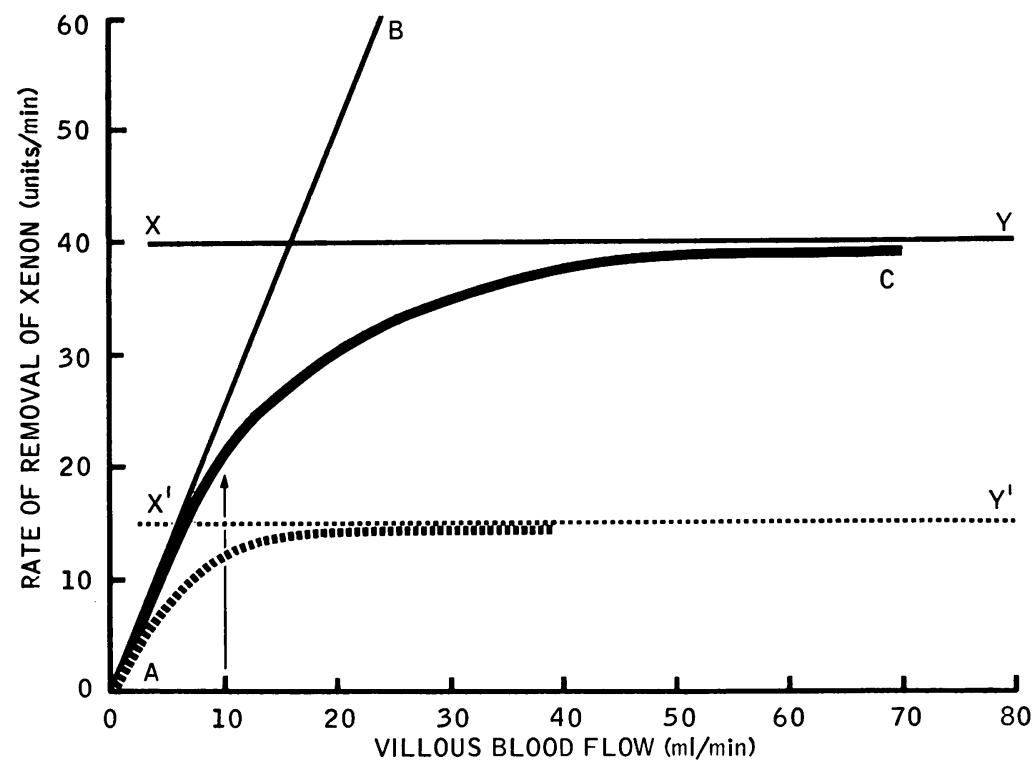

FIG. 10. The offect on the relation between blood flow and Xenon removal of limited access of lumen saline to the surface of the villus. This is a modifcation of Figure 6. Limited access of saline to the villus surface has the effect of lowering $X Y$ to $X^{\prime} Y^{\prime}$, and so displacing the plot $A C$ further away from the 'ideal' $A B$.

upon the rate of removal of Xenon by blood perfusing each level of the villus is shown in Fig. 11, which represents a blood flow evenly distributed to all levels of the villus.

$L$ represents the rate that would be possible in the ideal blood flow limited system.

$M$ represents the rate with the diffusion barrier of the epithelial cell.

$\mathrm{N}$ represents the rate with, in addition to diffusion, the limited access to the surface. It shows how this factor almost totally prevents removal by blood perfusing the base but does not interfere with removal at the tip.

If the area below $\mathrm{L}$ were considered to represent the total actual blood flow, then the area below $\mathrm{N}$ represents the apparent blood flow indicated by the rate of removal of Xenon from the free lumen. The shape of $\mathbf{N}$ demonstrates that a minor reduction in flow in the tips of the villi would cause a major reduction in the total rate of Xenon removal; and a change in the degree of access of fluid to the villous surface would cause a shift of the line $\mathbf{N}$ and alter the rate of Xenon removal quite independent of blood flow. In summary, the rate of removal of Xenon can give neither a quantitative nor a qualitative measure of total villous blood flow because it is limited by the other factors of fluid access (and to a minor degree by diffusion) that together are of greater magnitude than, and are independent of, total blood flow. In theory this problem could be overcome by violently mixing the saline in the lumen to force access between the villi, but in practice this produces a reflex vasoconstriction and therefore cannot be used.
Although we must accept that the rate of Xenon removal is not a measure of total villous blood flow, it could be used as an integrated measure of the blood flow to which Xenon has apparent full access over a period of time, and could be called the 'accessible blood flow'. This accessible blood flow would have three components.

1 The blood flow to the tip of the villi, fully accessible at all times to lumen fluid.

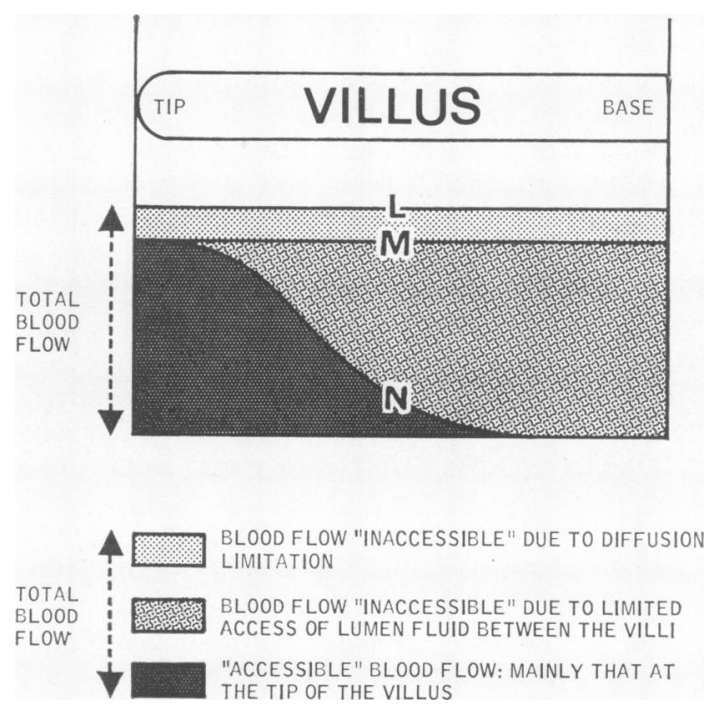

FIG. 11. A diagrammatic representation of the factors affecting the rate of removal of Xenon from the small gut lumen by blood perfusing the villi. Countercurrent exchange, an additional factor, is not represented. 
2 The blood flow only intermittently accessible to lumen fluid depending on elongation of villi to bring the sides of the villi into the freely circulating lumen fluid. If lumen fluid had access in this way to the sides of the villi for only $50 \%$ of the time, then accessible blood flow in this part would be $50 \%$ of total blood flow.

3 The blood flow continuously but only partially accessible to lumen fluid because of slow circulation of the lumen fluid between the villi. If this slow circulation of lumen fluid, dependent upon gut and villous motility, allows only a $40 \%$ saturation with Xenon of blood perfusing any particular level of a villus, then the accessible blood flow of that level will be $40 \%$ of its total blood flow.

Obviously in a continuously moving tissue there will never be a static situation, and at any one villus the three components will change from moment to moment. But over the relatively large area of a loop of small gut the total values of all these changing components will be the overall accessible blood flow for that loop.

To express blood flow in these terms is in fact more meaningful than in terms of total villous blood flow, because it is to this same accessible blood flow that other solutes, such as food substances, also have access. The study of the role of blood flow in relation to absorption would be more correctly studied using this as the measure rather than total blood flow.

A POSSIBLE COUNTERCURRENT EXCHANGE OF XENON Whilst Xenon removal might theoretically be dependent upon 'accessible blood flow', this interpretation alone does not explain the frequent extremely low absolute values, nor the lack of correlation between Xenon removal and either total blood flow (Fig. 3) or mucosal oxygen tension (Fig. 5). These suggest that there might be yet another factor delaying Xenon removal, and which would invalidate its use even as a measure of 'accessible blood flow'. A possible factor could be a countercurrent exchange between arteriole and venule.

The anatomical basis for such an exchange lies in the long course of these vessels between submucosa and villous tip (Fig. 8). They lie close to each other and blood flows in them in opposite directions, so that Xenon could diffuse from the high concentration in the vein to the low concentration in the arteriole and so return to the villous tip. Blood arising at the villous tip would therefore have a reduced capacity to carry more Xenon. This is illustrated in Figure 12. This would reduce the rate of removal of Xenon from the lumen and cause it to underestimate blood flow. Such an exchange will be efficient only if the rate of diffusion of Xenon through the vessel walls is fast enough.
Recent work of Staub (1961) has shown that in the lungs gas diffusion can occur rapidly into arterioles of over $50 \mu$ diameter. The efficiency of countercurrent exchange in the gut will be reduced by the removal of offloaded Xenon by the local capillaries of crypt and villus and by the dilution of Xenon in the vein when capillary blood enters from tissue inaccessible to Xenon in the lumen. In a steady state, it will not appear as a separate exponential in Xenon disappearance curves because its rate is directly dependent upon the rate of removal of Xenon from the villous tip.

We have not ourselves investigated this further and therefore produce no direct evidence about it.

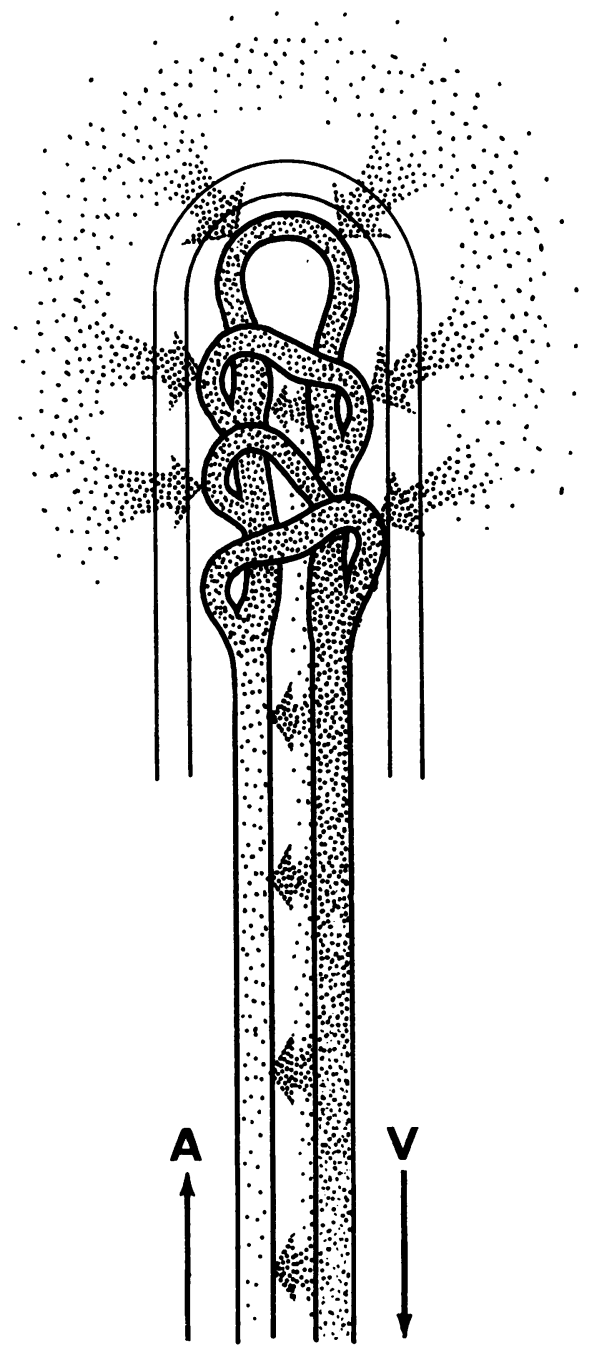

FIG. 12. A diagrammatic representation of the countercurrent exchange that might occur from the venule $(V)$ to the arteriole $(A)$ in a villus. 
But Lundgren and Kampp (1966) mention unpublished work in progress that supports just such an exchange after intraarterial injection of Krypton ${ }^{85}$ into the small guts of cats. They propose that this accounts for the very rapid phase of Krypton washout that could only otherwise be accounted for by a direct arteriovenous shunting of up to $50 \%$ of total blood flow to the gut, or alternatively by a compartment of blood flow of 400 to $1,400 \mathrm{ml} . / \mathrm{min} . / 100 \mathrm{~g}$., which is unrealistic. An exchange of a similar magnitude in the dog would considerably reduce the rate of removal of Xenon from lumen fluid and invalidate its use as a measure even of 'accessible blood flow'.

\section{CONCLUSIONS}

Our observations in the dog gut preclude the use of the rate of removal of Xenon from the lumen as a measure of total mucosal or of total villous blood flow. The possibility of a countercurrent exchange precludes its use to measure even 'accessible blood flow'. Similarly in the kidney the far more efficient countercurrent exchange in the rete has been shown by Aukland and Berliner (1964) and Thorburn, Kopald, Herd, Hollenberg, O'Morchoe, and Barger (1963) to preclude similar methods as a measure of medullary blood flow. The same considerations preclude the use of other diffusible gases, and also of heat exchange which is governed by the same factors.

The observations raise the problem of ever validating such indirect methods of measuring blood flow. Several approaches are taken by most workers. The finding of a single exponential in the washout studies in the myocardium was taken by Cohen, Elliott, and Gortin (1964) to validate the method as a measure of blood flow, but this in fact only indicates a homogeneous relationship between tissue mass and blood flow, and will be produced by a diffusion limited system and by a countercurrent exchange system, and so it does not necessarily demonstrate that removal of Xenon is dependent only upon blood flow. Reactive hyperaemia has been used as a physiological method of increasing nutritive blood flow, and the concurrent increase of Xenon or Krypton removal has been taken as proof that their removal is dependent only upon blood flow (e.g., Holzman, Wagner, Iio, Rabinowitz, and Zierler, 1964). The same experiment in the small gut gives the same type of result but this can be explained by an alternative mechanism so that it does not necessarily validate the method as a measure of blood flow. This mechanism is the gradual loading, during the period of ischaemia, of the bases of the villi and the crypt area and the villous cores. When blood is flowing at a steady rate lumen fluid has such slow access to these parts that little Xenon can be removed through them. With no blood flowing, however, they can be slowly loaded so that when blood flows again it removes this Xenon, causing a rapid rate of removal for a short time until equilibrium is reestablished. This phase of rapid removal would occur even if blood flow were at the same rate as before the occlusion, and would mimic the effect of a period of high blood flow.

A similar situation could be envisaged in those methods of measuring muscle blood flow from the rate of clearance of Xenon after a direct injection of Xenon dissolved in saline (e.g., Lassen, Lindbjerg, and Dahn, 1965; Lassen, Lindbjerg, and Munck, 1964; Munck, Lysgaard, Pontonnier, Lefévre, and Lassen, 1964; Holzman et al., 1964). The basic assumption is made that diffusion of Xenon into the surrounding muscle is very rapid. But if, on the other hand, the injected saline were to remain as a reservoir with slow diffusion of Xenon through it and out of it, then the period of ischaemia might allow a loading of surrounding tissue so that the return of blood flow would cause an initial period of rapid removal of Xenon that would not, however, be a reflection simply of high blood flow. To avoid these objections the correct time to give the injection of Xenon in these experiments is not before the arterial occlusion is started, but immediately before it is released. The observation of Holzman that the volume of the injection made no difference to the rate of removal of Xenon appears to suggest that these considerations are not of great importance, although a large injection volume will have a correspondingly large area of contact with muscle tissue through which Xenon could diffuse, and this would minimize the effects of the injection volume without proving that removal out of the injectate is not a rate limiting factor. It is easy to accept that a method that fulfils some simple criteria and gives a reasonable result is also one that gives a meaningful result. This is unsafe, because such a method may give results under altered and experimental conditions that are influenced more by the coincident variables of the experiment than by the primary variable. Conclusions drawn from such a situation may then be totally invalid, and the fact that they are reasonable is no proof that they are meaningful.

\section{SUMMARY}

An attempt was made to measure mucosal blood flow in the small gut from the rate of disappearance of radioactive Xenon dissolved in isotonic fluid from a loop of small gut. Initial experiments suggested that this disappearance was blood-flow dependent 
because there was a mono-exponential rate of disappearance, and because after temporary occlusion of the artery supplying the loop there was a period of rapid removal of Xenon that corresponded in time to the period of reactive hyperaemia. The values calculated from Xenon disappearance rates, however, were much lower than those obtained by other methods. Moreover, in experiments altering blood flow by intraarterial infusions of bradykinin and vasopressin, no correlation was obtained between the rate of removal of Xenon (the suggested measure of mucosal blood flow) and total small gut blood flow measured by collecting venous effluent. Furthermore, although the oxygen consumption of the small gut remained constant over a wide range of blood flow, there was no correlation between the rate of disappearance of Xenon and lumen oxygen tension, which is taken as a measure of mucosal oxygen tension.

Possible limiting factors of this method have been investigated and discussed. It seems that:

A Under any circumstances the method could measure only villous blood flow because the lumen fluid has no access into the crypts.

B The rate of diffusion of Xenon through the villous epithelial cell would not be rate limiting over the range of blood flows which might be observed.

$\mathrm{C}$ The villi in dogs are tightly packed and are continuously contracting and relaxing. Thus lumen fluid has only intermittent access to varying portions of individual villi, and therefore to only a corresponding proportion of their blood flow.

Thus theoretically one might be able to measure blood flow through the villous area in contact with lumen fluid-'accessible blood flow'. This is supported by anatomical studies which demonstrate, in contrast to previous findings, that the central arteriole gives off a series of lateral branches to the capillary network of the villus, and that this network is not simply a series of vessels draining the villous tips.

These observations might account for the apparently low values calculated for blood flow, but they would not account for the lack of correlation between these values and lumen oxygen tension. It is possible that the anomalous behaviour of Xenon disappearance can be explained on the basis of a countercurrent exchange between the central artery and vein in each villus.

In other species anatomical features in the villi and the pattern of villous motility will differ from those in the dog. But the basic considerations that have been outlined will still be relevant.

The implications of these observations in relation to other methods of measuring blood flow by radioactive gas clearance are discussed.

\section{APPENDIX}

Warren (1939) in a $12 \mathrm{~kg}$. dog found a ratio of mucosal surface area to serosal surface area of 8.5 in jejunum and 6.78 in lower ileum. Similar measurements on histological sections from our experimental dogs confirm this difference, due mainly to the villi of the ileum being shorter than those of the jejunum. The bases of the villi are slightly constricted and the consequent intervening flat area is occupied by the mouths of the crypts. The size of this flat area is relatively small when compared with the rat, for which Fisher and Parsons (1950) applied a relevant correction; we have made an approximate similar correction, and the average values for surface area we found for $10 \mathrm{~cm}$. loops are 550 sq. $\mathrm{cm}$. (13 jejunal specimens) and $370 \mathrm{sq} . \mathrm{cm}$. (three ileal specimens). These values are very similar to those of Warren (1939). For the purposes of calculation, we have taken the average of these values, 460 sq. $\mathrm{cm}$. Such assessments of surface area are only approximations to the true value in life, when the villi are in constant motion and when blood under pressure in the blood vessels appears to act as a fluid skeleton, elongating the villi. This is suggested by the instantaneous retraction of villi when mesenteric blood flow is reduced either by occlusion or sharp injection of saline against the main flow of blood in the mesenteric artery.

We wish to thank the Board of Governors of St. Bartholomew's Hospital and the Dowager Countess Eleanor Peel Trust for grants in support of this work, and Dr. A. Guz for stimulating discussion.

\section{REFERENCES}

Aukland, K., and Berliner, R. W. (1964). Renal medullary countercurrent system studied with hydrogen gas. Circulat. Res., 15, 430-442.

Code, C. F., Bass, P., McClary, G. B., Jr., Newnum, R. L., and Orvis, A. L. (1960). Absorption of water, sodium and potassium in small intestine of dogs. Amer. J. Physiol., 199, 281-288.

Cohen, L. S., Elliott, W. C., and Gortin, R. (1964). Measurement of myocardial blood flow using krypton ${ }^{85}$. Ibid., 206, 997-999.

Conn, H. L., Jr. (1961). Equilibrium distribution of radioxenon in tissue: xenon-hemoglobin association curve. J. appl. Physiol., 16, $1065-1070$.

Dawson, A. M., Trenchard, D., and Guz, A. (1965). Small bowel tonometry: assessment of small gut mucosal oxygen tension in dog and man. Nature (Lond.), 206, 943-944.

Fisher, R. B., and Parsons, D. S. (1950). The gradient of mucosal surface area in the small intestine of the rat. J. Anat. (Lond.) 84, 272-282.

Grim, E. (1964). The flow of blood in the mesenteric vessels. In Handbook of Physiology, Sect. 2, Circulation, vol. II, pp. 1439-1456. American Physiological Society, Washington.

Hambleton, B. F. (1914). Note upon the movements of the intestinal villi. Amer. J. Physiol., 34, 446-447.

Holzman, G. B., Wagner, H. N., Jr., Iio, M., Rabinowitz, D., and Zierler, K. L. (1964). Measurement of muscle blood flow in the human forearm with radioactive krypton and xenon. Circulation, 30, 27-34. 
Jacobson, L. F., and Noer, R. J. (1952). The vascular pattern of the intestinal villi in various laboratory animals and man. Anat. Rec., 114, 85-101.

Jones, H. B. (1950). Respiratory system: nitrogen elimination. In Medical Physics, vol. II, pp. 855-871, edited by O. Glasser. Yearbook Publishers, Chicago.

Kety, S. S. (1951). The theory and applications of the exchange of inert gas at the lungs and tissues. Pharmacol. Rev., 3, 1-41.

Krogh, A. (1919). The rate of diffusion of gases through animal tissues, with some remarks on the coefficient of invasion. J. Physiol. Pharmacol. (Lond.), 52, 391-408.

Lassen, N. A., Høedt-Rasmussen, K., Lindbjerg, I., Pedersen, E., and Munck, O. (1963). Muscle blood flow determined by the use of xenon ${ }^{13 s}$. Scand. J. clin. Lab. Invest., 15, suppl. 76, 61.

_- Lindbjerg, I. F., and Munck, O. (1964). Measurement of bloodflow through skeletal muscle by intramuscular injection of xenon $^{133}$. Lancet, 1, 686-689.

- - , and Klee, A. (1965). Cerebral blood flow determined by saturation and desaturation with krypton ${ }^{85}$. Circulat. Res., 16, 26-32.

---, Lindbjerg, I. F., and Dahn, I. (1965). Validity of the xenon ${ }^{133}$ method for measurement of muscle blood flow evaluated by simultaneous venous occlusion plethysmography. Ibid., 16, 287-293.

Lindseth, E. (1960). Vascular flow patterns in the tissues of the dog intestine. Ph.D. Thesis, Minneapolis; University of Minnesota. Quoted by Grim (1964), p. 1443.

Longmuir, I. S., and Bourke, A. (1960). The measurement of the diffusion of oxygen through respiring tissue. Biochem. J., 76, 225-229.
Lundgren, O., and Kampp, M. (1966). The wash-out of intraarterially injected krypton ${ }^{85}$ from the intestine of the cat. Experientia (Basel), 22, 268-270.

Munck, O., Lysgaard, H., Pontonnier, G., Lefévre, H., and Lassen, N. A. (1964). Measurement of blood-flow through uterine muscle by local injection of ${ }^{133}$ xenon. Lancet, $1,1421$.

Pittinger, C. B., Conn, H. L., Featherstone, R. M., Stickley, E., Levy, L., and Cullen, S. C. (1956). Observations on the kinetics of transfer of xenon and chloroform between blood and brain in the dog. Anesthesiology, 17, 523-530.

Rayner, R. R., MacLean, L. D., and Grim, E. (1960). Intestinal tissue blood flow in shock due to endotoxin. Circulat. Res., 8, 1212-1217.

Ross, R. S., Ueda, K., Lichtlen, P. R., and Rees, J. R. (1964). Measurement of myocardial blood flow in animals and man by selective injection of radioactive inert gas into the coronary arteries. Ibid., 15, 28-41.

Staub, N. C. (1961). Microcirculation of the lung utilizing very rapid freezing. Angiology, 12, 469-472.

Thorburn, G. D., Kopald, H. H., Herd, J. A., Hollenberg, M., O'Morchoe, C. C. C., and Barger, A. C. (1963). Intrarenal distribution of nutrient blood flow determined with krypton"s in the unanaesthetized dog. Circulat. Res., 13, 290-307.

Warren, R. (1939). Serosal and mucosal dimensions at different levels of the dog's small intestine. Anat. Rec., 75, 427-437.

Weiner, D. (1961). Kinetics of distribution of $\mathrm{D}_{2} \mathrm{O}$ in the tissues of canine ileum. Thesis, Minneapolis, University of Minnesota. Quoted by Grim (1964), p. 1444. 